\title{
O DESENVOLVIMENTO PROFISSIONAL DOCENTE NO TRABALHO COM A ALFABETIZAÇÃO DE IDOSOS
}

\section{Adriana Alves Fernandes Vicentini \\ Universidade Federal Rural do Rio de \\ Janeiro}

\section{Daniela Gobbo Donadon Gazoli}

Professora da Uniesp

Guilherme do Val Toledo Prado

Universidade Estadual de Campinas

\section{Resumo:}

Este texto tem como objetivo principal abordar o desenvolvimento profissional docente no trabalho com a alfabetização de idosos, tendo a discussão da experiência, em Larrosa e de linguagem, em Bakhtin, como dispositivos disparadores desse processo. Compartilha-se a trajetória de uma professora em uma sala de alfabetização de idosos em uma rede municipal de ensino de uma cidade do interior de São Paulo, desde 2009. A prática educativa vivenciada como docente com o idoso constitui-se como um referencial que se encontra problematizado criticamente, com o intuito de potencializar o percurso de desenvolvimento profissional. Discute-se a relevância de tais conceitos como fundantes para este processo.

Palavras chave: Experiência de Ensino; Linguagem; Alfabetização de Idosos. 


\title{
THE TEACHER PROFESSIONAL DEVELOPMENT IN LITERACY WORK WITH THE ELDERLY
}

\begin{abstract}
This paper discusses the professional development of teachers with the elderly students, with the discussion of the experience and language as trigger devices. It shares the trajectory of a teacher in a literacy classroom for elderly students in a municipal school at a city in the inner state of São Paulo, for four years. The educational practice experienced as a teacher with the elderly students was established as a reference that is questioned critically, in order to enhance the professional development path. Action and experience act at the same time and appear as a stabilization point, it also represents a mode of opening.
\end{abstract}

Keywords: Teaching experience; Language; Elderly Literacy. 


\section{Apresentação}

$\mathrm{O}$ presente texto tem como objetivo principal abordar o desenvolvimento profissional docente na Educação de Idosos $^{1}$. Para isso, compartilha-se a experiência de uma professora em sala de alfabetização de idosos na rede de ensino de uma cidade do interior de São Paulo. A professora lecionou nessa sala desde o ano de 2009 até 2013. Seu trabalho foi fonte de produção de dados para duas pesquisas ${ }^{2}$, que embasam o presente artigo.

Quanto ao método utilizado para esta escrita, este é entendido como estudo de caso, que segundo Lüdke e André (1986) é “o estudo de um caso, (...), como o de uma professora competente de uma escola pública" (p. 17). Os dados aqui apresentados foram coletados usando o instrumento de coleta conhecido como Diário de Campo da docente. Alguns trechos foram capturados por serem considerados relevantes para a discussão do tema e por isso foram transcritos para análise. Parte-se, também, da transcrição de trechos de narrativas produzidas pelos alunos da turma em questão.

Dessa forma, para organização dessa escrita, primeiramente discorre-se brevemente sobre o conceito de desenvolvimento profissional docente e, posteriormente, narra-se seu percurso profissional, analisando-o como possibilidade de compartilhar estabilidades e aberturas na ação educativa com os idosos. Assim, no processo observado, ao mesmo tempo em que a ação e a experiência docente apresentam-se como pontos de estabilização também se constituem como um modo de abertura. Isto é, a prática e a experiência como ponto de apoio para compreender e significar novas situações

\footnotetext{
$1^{\urcorner}$No contexto deste texto assume-se a Educação de Idosos como uma parte integrante da modalidade Educação de Jovens e Adultos - EJA.

$2\urcorner$ Vicentini (2012) e Gazoli (2013).

Olh@res, Guarulhos, v. 2, n. 2, p. 424-448. Dezembro, 2014.
} 
formativas também se revelam como um lançamento ao desconhecido em um movimento constante de busca por formação e abertura.

Igualmente, parte-se da compreensão de linguagem enquanto acesso ao mundo do educando, fundamental para aproximá-lo do processo de ensino e de aprendizagem. Transgredir a linguagem das consignas de atividades a favor de uma escuta alteritária - que considera o dizer do outro em uma relação dialógica - possibilita apreender os diferentes modos de aprender dos idosos, a partir da investigação dos indícios e interpretações produzidos neste processo. Suas narrativas mostram-se como dispositivos potentes para ressignificação do vivido no contexto da aprendizagem escolar.

Há que se considerar que uma importante dimensão do desenvolvimento profissional docente acontece no trabalho educativo com esses sujeitos, os quais procuram os espaços escolares não somente como lugares de aprendizagem, mas de convivência. Em tais espaços o alfabetizar-se não se constitui como único objetivo, desta forma necessita-se de uma abordagem complexa e diferenciada, bem como de um olhar estratégico relevante para gerar novas e produtivas aprendizagens junto aos estudantes idosos.

\section{Desenvolvimento Profissional Docente}

Pensar o conceito de desenvolvimento profissional docente fazse importante no movimento da ação cotidiana da professora no trabalho de alfabetização com idosos. Assim, o conceito designado para nomear a chamada formação continuada é denominado desenvolvimento profissional, o qual para Garcia (1995) é a expressão "que melhor se adapta à concepção atual do professor como profissional do ensino"(p. 55). Não se trata, somente, de uma mudança terminológica, mas de entender a formação continuada sob uma outra amplitude. Para Garcia (1995) a ideia de continuum deve permear toda 
a trajetória da formação docente. Diante desta perspectiva, tanto a formação inicial quanto a formação continuada nos remetem a pensar o processo formativo como desencadeamento do desenvolvimento profissional docente.

Nas palavras do autor,

A noção de desenvolvimento tem uma conotação de evolução e de continuidade que nos parece superar a tradicional justaposição entre formação inicial e aperfeiçoamento dos professores. (GARCIA,p. 55)

$\mathrm{Na}$ literatura, muitos autores têm se voltado a olhar, mais detidamente, o desenvolvimento profissional dos professores, dentre os quais destacam-se: Nóvoa (1995), Garcia (1995), Leite (2000), Giovanni (2003), Imbernón (2004), Vicentini (2012), dentre outros.

Sendo a ideia de continuum (GARCIA, 1995) olhada sob o prisma formativo em constante desenvolvimento, a aprendizagem é entendida como veículo permanente e norteador de todo trajeto profissional. Sob esses aspectos, os aprendizados são considerados inacabados e temporários, remetendo-se à compreensão de movimentos que os conhecimentos sofrem no decorrer do tempo. Inacabados porque, continuamente, encontram-se em movimento permanente, e temporários porque são provisórios no sentido de que, a cada nova experiência e aprendizagem, o desenvolvimento do profissional docente reconfigura-se.

Neste sentido saltos qualitativos e quantitativos no percurso profissional docente são compreendidos como essenciais sob tal prisma, sendo este permeado pelas dimensões pessoais e profissionais; conferindo a estas um caráter unitário e indissociável.

Nóvoa (1995), por sua vez, entende que a ideia de desenvolvimento profissional associa-se, ainda, a mais uma dimensão: envolve compreender o professor como protagonista de sua profissão. A partir deste ponto de vista, o docente deve atuar, inclusive, diretamente Olh@res, Guarulhos, v. 2, n. 2, p. 424-448. Dezembro, 2014. 
na implementação das políticas públicas educacionais que influenciam e direcionam os rumos da educação, para além do espaço escolar restrito, entendendo seu alcance em um âmbito muito mais amplo.

Para Nóvoa (1995),

A formação pode estimular o desenvolvimento profissional dos professores, no quadro de uma autonomia contextualizada da profissão docente. Importa valorizar paradigmas de formação que promovam a preparação de professores reflexivos, que assumam a responsabilidade do seu próprio desenvolvimento profissional e que participem como protagonistas na implementação de políticas educativas. (p. 27)

Imbernón (2004), também discute o conceito, explorando algumas dimensões singulares:

Um conjunto de fatores que possibilitam ou impedem que o professor progrida em sua carreira profissional. A melhoria da formação ajudará esse desenvolvimento, mas a melhoria de outros fatores (salário, estruturas, níveis de decisão, níveis de participação, carreira, clima de trabalho, legislação trabalhista, etc.) tem papel decisivo nesse desenvolvimento (p.44).

O autor pontua, com destaque, o lugar das condições de trabalho dos professores e da concretude da profissão docente que, também, constitui-se como parte do processo de desenvolvimento profissional. Tratam-se de elementos imprescindíveis que constituem, inegavelmente, o trajeto de todos os educadores dentro do conceito aqui abordado.

Os autores aqui discutidos colaboram para o enriquecimento do conceito de desenvolvimento profissional docente, contribuindo para a compreensão da sua complexidade. Neste sentido, as abordagens por eles tratadas permitem observar que o referido conceito não é simples e que são necessários diversos fundamentos, em diferentes dimensões, para que seu entendimento efetivo aconteça de forma a favorecer a aprendizagem de educadores e educandos.

Pensar sob essa amplitude nos ensina que os conhecimentos que movimentam o refletir sobre o universo pedagógico são extremamente Olh@res, Guarulhos, v. 2, n. 2, p. 424-448. Dezembro, 2014. 
importantes, porém não são redentores, pois as condições exemplificadas pelos autores nos mostram aspectos que denotam um olhar mais problematizador sobre o desenvolvimento profissional docente.

Esse, ao ser relacionado com o campo de atuação com os idosos, possibilita encontrar desafios singulares que lançam os educadores ao redimensionar da finalidade da ação educativa. Nesse sentido, nas próximas linhas centraliza-se uma discussão sobre o viver/fazer educacional com os idosos.

\section{O trabalho com Alfabetização de Idosos}

No ano de 2009, a professora $\mathrm{Ana}^{3}$ iniciou o trabalho com a Alfabetização de Idosos (ALFI), o qual gerou os dados que constituem a base de análise deste artigo. Tratava-se de uma sala diurna, com funcionamento em um espaço não escolar. A reflexão deste texto parte, inicialmente, de um relatório datado de 19.08.2009, elaborado pela docente, que retrata o perfil da sala de aula, bem como as condições de trabalho, apresentando o contexto em que se situa esta discussão:

A classe possui 15 alunos matriculados e frequentes, sendo 14 destes, idosos. O espaço físico é reduzido e pouco iluminado, o que dificulta a visualização das atividades que são escritas na lousa, pois a luz reflete na mesma, que pelo fato de ser branca complica ainda mais. É preciso ressaltar, ainda, que a referida lousa está gasta e tenho dificuldade para apagá-la, visto que há manchas não removíveis.

A sala de alfabetização também se localiza entre a sala de espera para atendimento da assistência social e uma sala de reuniões de atendimento ao público, isso significa que, mesmo fechando a porta, há barulho que incomoda o andamento da aula.

3 Nome fictício.

Olh@res, Guarulhos, v. 2, n. 2, p. 424-448. Dezembro, 2014. 
Um outro ponto refere-se a falta de espaço adequado para intervalo, apesar de existir uma sala ao lado, como já foi mencionado a mesma é ocupada para periódicas reuniões.

Uma opção para a solução desta problemática seria ocupar uma sala ventilada, espaçosa e clara que há na parte superior do prédio, mas há uma enorme escada desconfortável para alunos idosos, podendo ocasionar acidentes.

O registro acima descreve vários pontos relacionados à estrutura física de trabalho, pois se tratava de um projeto de parceria entre a Secretaria de Educação e a Secretaria de Promoção Social, o que implicava em as aulas acontecerem em espaços não escolares.

Esse relatório, como outros, também referenciava a primeira experiência da docente em lecionar com/para idosos. Apesar desse desafio, nos primeiros dias desenvolveu um trabalho de conquista daquele grupo, pois identificou estudantes com muitas curiosidades: quem era aquela professora que estava agora lecionando para eles depois de alguns anos "no lugar" da outra docente que eles já conheciam e tinham construído uma relação de afinidade? Mudaria toda a forma de ensino daquele espaço frequentado por eles há anos? Aprenderiam outros/novos conteúdos? Estas eram algumas perguntas apresentadas à professora naquele começo de trabalho, perguntas por ela registradas em um diário de campo.

Diante dessa situação, pode-se afirmar que o primeiro desafio foi desenvolver o que Nóvoa (2009) nomeia como tacto pedagógico, que é a capacidade de comunicação, uma certa sensibilidade de compreensão do modo de ser professor junto aos estudantes idosos. Nas palavras do autor é:

A capacidade de relação e de comunicação sem a qual não se cumpre o ato de educar. É também essa serenidade de quem é capaz de se dar o respeito, conquistando os alunos para o trabalho escolar. Saber conduzir alguém para a outra margem, o conhecimento, não está ao alcance de todos. No ensino, as dimensões profissionais cruzam-se sempre, inevitavelmente, com as dimensões pessoais (NÓVOA, 2009, p. 30-31).

Olh@res, Guarulhos, v. 2, n. 2, p. 424-448. Dezembro, 2014. 
Também Vicentini (2012), ao discutir a natureza relacional deste conceito, afirma:

\begin{abstract}
Nessa perspectiva, o tacto pedagógico é um dispositivo regulador da profissão, pois além de ser um elemento norteador e relacional da ação pedagógica em sala de aula ele também contribui para a minimização da evasão escolar. Desse modo, podemos dizer que ele possui um sentido estratégico quanto à formação docente: pensá-la a favor da aprendizagem discente (p.108).
\end{abstract}

Considerando as discussões apresentadas, a professora entendeu que era necessário compreender as lógicas pessoais e experienciais daqueles estudantes. Aqueles idosos possuíam uma compreensão social de escola como lugar onde professor ensina, aluno aprende e o conhecimento é transmitido. Devido a isso, solicitavam correções no caderno, atividades que envolviam silabação, contas desconectadas de situações problemas, entre outras práticas tradicionais. No entanto, a docente esperava, inicialmente, desenvolver atividades mais desafiadoras, trabalhar com projetos diversos, alfabetizar com textos, mas aprendeu que era necessário introduzir tais práticas paulatinamente, com o objetivo de viabilizar a permanência do grupo.

Além disso, aparentemente contraditório era o fato de tal aprendizagem não ser a prioridade dos idosos, pois muitos narravam à necessidade de participar de um grupo, de estar e coexistir em espaços de convivência humana.

No final de 2009, por intermédio de uma solicitação da professora, a sala mudou de local, sendo realocada para um espaço de uma igreja do bairro. Na época, a docente já conhecia melhor o grupo, nesse sentido, seu relatório já elucidava mais apontamentos sobre o trabalho pedagógico:

A sala de alfabetização de idosos está localizada em uma das salas da Igreja do Belo Ramo e possui 16 alunos. A referida classe possui alunos em diferentes momentos da alfabetização: iniciantes, em processo e mais experientes.

Olh@res, Guarulhos, v. 2, n. 2, p. 424-448. Dezembro, 2014. 
Em relação à avaliação do processo ensino-aprendizagem dos estudantes, podemos afirmar que, especialmente os iniciantes, necessitam de bastante atenção por parte da professora, esse fato me faz organizar um planejamento didático estratégico a fim de atender as singularidades desses idosos. Contudo, pode-se, de maneira geral, observar avanços importantes no aprendizado, assim como, em relação à convivência do grupo. Trata-se de pessoas que gostam de conviver, de frequentar a escola, sendo este muito mais que um momento de aprender as letras, mas uma forma de inclusão social, de sentido para a vida.

Para 2010, pretendo adotar um livro didático como norteador do trabalho com a intenção de oferecer aos alunos mais um recurso de estudo e aprofundamento das temáticas estudadas.

Pretendo, também, trabalhar com um projeto que envolva poesia e música, pois percebi que esses recursos envolvem a dimensão afetiva de modo significativo e, nesse sentido, acredito que a esfera cognitiva será mais bem acessada e poderá ter maior efeito na aprendizagem dos alunos.

Estrutura física

No segundo semestre o lanche foi oferecido gentilmente pela EMEF F. A. T. L., bem como, materiais escolares para os estudantes e objetos de uso cotidiano como giz, apagador, copos descartáveis etc.

$E^{E}$ preciso ressaltar que a atual sala possui condições importantes para o desenvolvimento das aulas: é clara, ventilada, espaçosa, sendo a iluminação relativamente adequada para os idosos.

A sala fora disponibilizada pela igreja, sem custo algum.

Atividades extraclasse

Neste ano participamos de bailes temáticos promovidos pelo Centro de Vivência da $3^{a}$ idade, assistimos filmes utilizando a sala de projeção do Centro de Vivência, fomos à Holambra, na exposição de Lasar Segall, no shopping Dom Pedro, no Parque Ecológico de Paulínia, no Parque do Jambeiro em Campinas. Realizamos uma exposição de fotos das turmas dos 4 núcleos do ALFI, localizados em quatro bairros da cidade.

Naquela ocasião, a professora já se questionava sobre a finalidade da Educação de Idosos. Dentre estudos diversos encontrou Finger e Asún (2003), que tratam da importância de o professor olhar criticamente e se perguntar sobre a instrumentalização do ensino na 
atual sociedade industrializada. Segundo tais estudiosos, é preciso “desvendar os fundamentos e traduzi-los em práticas correspondentes de educação de adultos". (p.15) Uma saída é pensar tal segmento educacional como uma ferramenta no entendimento do mundo em que se vive, como uma forma de se relacionar consigo, com os outros e com o ambiente de maneira responsável. Assim, é necessário produzir um olhar crítico quanto aos fundamentos que orientam e/ou que estão subjacentes à Educação de Idosos em nossa sociedade.

O conceito de instrumentalização possibilitou maior compreensão no trabalho com os idosos, sendo que, na perspectiva dos alunos, o objetivo da escola para parte do grupo era aprender e para os demais era a construção da convivência com as pessoas da mesma faixa etária.

A partir do estudo dos autores citados e da realidade vivida pela professora com o grupo, ela identificou-se com a maioria dos profissionais que atuam com a Educação de Adultos no Brasil, uma vez que eles deparam-se, geralmente, com a precarização de sua própria formação, pois os cursos de Graduação ainda pouco tratam as especificidades da atuação com adultos e idosos no campo da educação e, quando o fazem, trabalham de modo superficial e efêmero.

Há, de fato, muito o que produzir em termos de investigação, quanto à formação do educador de idosos, bem como, muitas ações a problematizar: desde a formação inicial com a presença de uma disciplina na graduação que trate dessa temática, até nas próprias redes públicas de ensino, que ainda pouco oferecem ou se preocupam com o desenvolvimento profissional docente. Se realmente há preocupação, esta pouco se explicita na prática do cotidiano dos sistemas educacionais. Isso pode ser evidenciado através de ações recorrentes, como a eventual ou a nenhuma existência de encontros de formação sistemáticos, considerando a especificidade do referido segmento educacional (VICENTINI, 2012). 
Podemos dizer que o critério da profissionalização do educador na Educação de Jovens e Adultos (EJA) - que entendemos como compatível com a discussão aqui sustentada sobre a Educação de Idosos -, tem sido colocado como fundamental (CANÁRIO, 2000), uma vez que a ele é designada a tarefa de contribuir com a formação do sujeito que possui experiências e saberes já experimentados ao longo de sua vida. Não se trata de firmar uma dicotomia irrelevante entre professor de crianças e educador de adultos, mas de reconhecer que são campos de investigação com singularidades pertinentes a demandas e reflexões singulares.

Apoiando-se em Canário (2000), defende-se que a profissionalização do educador de EJA permite vislumbrar a perspectiva do desenvolvimento de diversas possibilidades de ações nesse campo, como por exemplo, a intensificação de produção de material de apoio ao profissional, a afirmação/sistematização de um campo da didática que apoie e construa com o educador os saberes pertinentes às necessidades dos alunos, neste caso na Educação de Idosos, em uma relação de diálogo e produção de conhecimento.

É preciso que o repertório prévio do aluno seja valorizado de maneira a entender que a realidade é o ponto de partida: faz-se importante "imitar o mundo", ou seja, aproximar-se dele para nele interferir.

Nesse sentido, dialoga-se novamente com Nóvoa (2009), ao dizer que a formação de professores "deve passar para dentro da profissão" (p.36). Entende-se que se faz necessário firmar o lugar do professor de idosos, ou seja, o que tal docente tem a dizer sobre sua experiência? Quais as práticas que promoveram a aprendizagem dos alunos? Quais dúvidas e dilemas? Quais ideias, propostas e situações experienciais têm para resolução de situações diversas vividas no contexto da docência com idosos? 
Se o sentido da profissão professor é construído dentro da própria profissão, no diálogo com diversas situações, contextos e experiências, então entende-se que o conhecimento profissional docente passa por sua voz e pelo dizer de seus saberes, que foram e são produzidos na e dentro da profissão. Ao pensar na Educação de Idosos, esse princípio é fundamental, pois é essencial que o docente produza conhecimentos, a partir de sua prática e estudo, sobre as singularidades da aprendizagem no mundo adulto, possibilitando um desenvolvimento profissional qualificado de forma a atender tais especificidades.

\section{A experiência docente como plataforma de estabilização e abertura}

Ao observar a prática da professora Ana, uma estratégia que tem se revelado promissora é a consideração e o desenvolvimento de um trabalho sistemático quanto às histórias de vida dos estudantes idosos. Trata-se de uma porta de entrada para o educador produzir e pensar o seu fazer.

Durante as aulas, os alunos narravam fragmentos de suas histórias de vida e não era incomum repeti-las inúmeras vezes em outros momentos. A repetição acontecia com a mesma riqueza de detalhes, com os mesmos atores e, inclusive, com os pontos de vista dos narradores.

$\mathrm{Na}$ sua condição de ouvinte, Ana, inicialmente, alertava os narradores da história já contada. A reação quase sempre era prosseguir o assunto, apenas comentando a história.

Em razão disso, a docente desenvolveu um trabalho de leitura e apreciação de textos literários de diversos autores, que remetiam e promoviam o contar de histórias. No fim do ano de 2009, construíram um livro de memórias da classe. Na ocasião, a docente registrou:

Todos os dias estamos lendo trechos de textos que envolvem a temática da memória. Em especial, o texto "Menina do Olh@res, Guarulhos, v. 2, n. 2, p. 424-448. Dezembro, 2014. 
interior" de Raquel de Queiroz, provocou narrativas sobre a infância de um modo envolvente nos alunos.

Foi a partir dessa leitura, em especial, que os alunos encontraram apoio para produzirem seus próprios textos. Penso que o jeito como a autora escreve influenciou significativamente a escrita dos alunos.

Fizemos muitas reescritas, organizando as idéias e selecionando o que seria escrito no papel.

Optamos por digitar e organizar em forma de um livro da classe.

Conversamos como seria essa produção: discutimos o que é um prefácio, indice, enfim, a organização de um livro. Convidamos a professora Ana Aragão para prefaciar, inclusive a escrita do email foi trabalhada em sala de aula de modo coletivo (sua estrutura, linguagem e finalidade) depois resolvemos publicar.

A produção do livro sobre a autobiografia dos alunos não representou somente uma produção, mas implicou em muitas aprendizagens aos estudantes e à professora. Aprendizados de diferentes naturezas: modos de viver a infância e forma de vida em um dado tempo nesse país, pouco ou nenhum acesso à escola, concepções sobre a mesma.

Há dois textos, em especial, aqui destacados para exemplificar os aprendizados dos estudantes:

Eu cuidava de casa e ia levar almoço na roça e depois abanava café, tinha nove anos de idade. De tarde vinha para casa, tomava banho, jantava arroz, feijão, salada e pão caseiro quando minha mãe fazia.

Minha mãe dizia que não precisava passar roupa de roça, mas eu sempre fui caprichosa, principalmente com as roupas de meu pai, era mimada por ele, sempre me dizia que eu era muito inteligente.

Minha vida era trabalhosa, mas eu gostava. Só que meu pai não me deixava ir para escola porque tinha que ajudar minha mãe. Tirava água do poço e lavava roupa na tábua para depois, passar.

Nessa época via as crianças voltando da escola com seus materiais e eu levando almoço pro meu pai e irmão no cafezal e pensava: "poderia ser eu... Mas tô trabalhando igual a uma doida..."

Olh@res, Guarulhos, v. 2, n. 2, p. 424-448. Dezembro, 2014. 
O tempo passou e já adulta, inclusive, operada de hérnia encontrei uma menina pra me ajudar nos afazeres da casa e ela disse que iria fazer a matrícula na escola pra mim, mas meu marido disse que não, pois escola é pra criança, gente adulta, tem mente cansada, bati o pé, fui teimosa e comecei a estudar, agora tenho apoio de todos. (Nair ${ }^{4}, 72$ anos)

Quando eu era criança, só carpia roça de café, plantava milho e feijão com máquina. De sábado eu ficava em casa, fazia faxina e passava roupa. Com dez anos, comecei fazer pão, "aqueles pãozão dessa grossura", "aqueles pãozão gostoso". Fazia arroz, feijão, carne de porco e frango. Aprendi a fazer tudo de panela. Eu inventava bolo e depois que casei, aprendi fazer até camisa para o "véio".

Minha infância não foi boa porque com oito anos eu pregava aquelas enxadas "desse tamanzinho" para limpar tronco de café. Um dia, uma aranha pegou meu dedo e eu coloquei na boca, e só senti que tudo ficou branco. Pedi ajuda do vizinho que me deu um contra veneno. Quanto sofrimento, eu não tenho saudade daquele tempo! Eu reclamei com minha mãe dizendo que eu não tive infância e ela disse que a dela foi muito pior. (Aparecida, 72 anos)

As narrativas destacadas foram construídas a partir da oralidade das estudantes. Retratam o desenvolvimento da inteireza de uma vida, associada ao desejo de viver o aprender na escola.

Explicitam, inclusive, cenas da realidade de uma camada social vividas por volta das décadas de 1940 e 1950, anos em que as alunas referenciadas viveram a fase inicial de suas vidas. Revelam, ainda, certo modo de viver, costumes, papéis sociais, além do pouco acesso à escola. Mostram um contexto social em que parte importante da população vivia na Zona Rural. Em Romanelli (2012) encontram-se dados que indicam a distribuição da população no Brasil, que na década de 1940 era de $68 \%$ concentrada na Zona Rural e na década de 1950 era de 63,84\%. Portanto, a maior parte da população vivia na Zona Rural. Em Romanelli (2012, p. 78) há dados, ainda, que revelam as taxas de analfabetismos em 1940, de 54,11\%, e 1950, de 47,64\%.

4 Todos os nomes aqui referidos são fictícios.

Olh@res, Guarulhos, v. 2, n. 2, p. 424-448. Dezembro, 2014. 
Considerando os dados acima apresentados, pode-se encontrar o tempo das narrativas contadas pelas estudantes Aparecida e Nair. Certamente, estavam localizadas nas estatísticas pertencentes à Zona Rural de uma sociedade com alto índice de analfabetismo.

Os fragmentos das narrativas contadas pelas referidas estudantes relatam uma experiência que advém da reflexão do próprio viver. Benjamin (1994) discute a experiência como saber compartilhável:

Qual o valor de todo nosso patrimônio cultural, se a experiência não mais se vincula a nós? A horrível mixórdia de estilos e concepções de mundo do século passado mostrou-nos com tanta clareza aonde esses valores culturais podem nos conduzir, quando a experiência nos é subtraída, hipócrita ou sorrateiramente, que é hoje em dia uma prova de honradez confessar nossa pobreza. Sim, é preferível confessar que essa pobreza de experiência não é mais privada, mas de toda a humanidade. Surge assim uma nova barbárie. (p.115)

O referido autor valoriza as narrativas da experiência como fonte de "patrimônio cultural”. Já Larrosa (2004) afirma que "a experiência é o que nos passa, o que nos acontece, o que nos toca. Não o que se passa, não o que acontece, ou o que toca. A cada dia se passam muitas coisas porém, ao mesmo tempo, quase nada nos acontece" (p.115). Nesse sentido, para este último autor a experiência seria algo raro em tempos de tantas informações, em uma velocidade acelerada de produção e consumo, por isso:

A experiência, a possibilidade de que algo nos aconteça ou nos toque, requer um gesto de interrupção, um gesto que é quase impossível nos tempos que correm: requer parar para pensar, parar para olhar, parar para escutar, pensar mais devagar, olhar mais devagar, e escutar mais devagar; parar para sentir, sentir mais devagar, demorar-se nos detalhes, suspender a opinião, suspender o juízo, suspender a vontade, suspender o automatismo da ação, cultivar a atenção e a delicadeza, abrir os olhos e os ouvidos, falar sobre o que nos acontece, aprender a lentidão, escutar aos outros, cultivar a arte do encontro, calar muito, ter paciência e dar-se tempo e espaço. (LARROSA, 2004, p. 115)

Assim, pode-se entender que a experiência possui uma dimensão qualitativa, ou seja, ela não seria um evento qualquer. Ela possui uma Olh@res, Guarulhos, v. 2, n. 2, p. 424-448. Dezembro, 2014. 
esfera formativa. Algo que move o sujeito e, por essa razão, constitui a sua singularidade. Apesar de se caracterizar como algo identitário, ela expressa um contexto, sendo potente e possível de ser compartilhada.

Deste modo, ela pode formar um repertório de acontecimentos que podem ser narrados e partilhados, sendo assim, uma forma de produção de experiências outras e de construção de narrativas cada vez mais qualificadas.

Ao acessar as narrativas dos idosos, localiza-se um saber da experiência, uma vez que:

Se a experiência é o que nos acontece e se o saber da experiência tem a ver com a elaboração do sentido ou do sem-sentido do que nos acontece, trata-se de um saber finito, ligado à existência de um indivíduo ou de uma comunidade humana particular. $\mathrm{Ou}$, de um modo ainda mais explícito, trata-se de um saber que revela ao homem concreto e singular, entendido individual ou coletivamente, o sentido ou o semsentido de sua própria existência, de sua própria finitude. Por isso o saber da experiência é um saber particular, subjetivo, relativo, contingente, pessoal. Se a experiência não é o que acontece, mas o que nos acontece, duas pessoas ainda que enfrentem o mesmo acontecimento, não fazem a mesma experiência. $\mathrm{O}$ acontecimento é comum, mas a experiência é para cada qual sua, singular e de alguma maneira irrepetível. O saber da experiência é um saber que não pode separar-se do indivíduo concreto em quem encarna. Não está, como o conhecimento científico, fora de nós, mas somente tem sentido no modo como configura uma personalidade, um caráter, uma sensibilidade ou, em definitivo, uma forma humana singular de estar no mundo que é por sua vez uma ética (um modo de conduzir-se) e uma estética (um estilo). Por isso também o saber da experiência não pode beneficiarse de qualquer alforria, quer dizer, ninguém pode aprender da experiência de outro a menos que essa experiência seja de algum modo revivida e tornada própria. (LARROSA, 2004, p.1)

Enfatiza-se que a dimensão das histórias de vida ainda merece maior atenção no trabalho com a formação dos educadores de idosos.

Olh@res, Guarulhos, v. 2, n. 2, p. 424-448. Dezembro, 2014. 
Trata-se de uma forma promissora de contribuir no campo da elaboração de uma teoria da formação de adultos, como bem ressaltam Nóvoa e Finger (1988). O uso das histórias de vida favorece a construção de conhecimentos acerca do desenvolvimento e da aprendizagem do sujeito adulto, propiciando a construção e o refinamento de princípios teórico-metodológicos no trabalho educativo com estes sujeitos.

Sabemos que o educador que lida com idoso compreende que o mesmo está imbricado na ação da vida civil: trabalho, atuação em diferentes espaços sociais. Esta condição é rica de experiência como contexto de produção da prática docente. Nesse sentido, é fundamental saber lidar com a imagem que os alunos têm de si: muitos se vêem, inicialmente, como incapazes, inseguros sobre suas próprias possibilidades de aprendizagem.

$\mathrm{Na}$ relação vivenciada entre professora e alunos, a experiência que compõe os idosos, extremamente rica e marcada por suas trajetórias de vida e, também, por suas inseguranças, encontra-se com a experiência do professor, imbuído de suas ideias sobre o como ensinar. Este encontro de experiências transforma a forma como ambos, professor e alunos, entendem o fazer docente, em um processo contínuo de negociação do que está posto e do que pode vir a ser.

Neste sentido, ao mesmo tempo em que a experiência é plataforma, ou seja, ponto de estabilização dos conhecimentos produzidos ao longo da trajetória profissional, ela é também a reconfiguração do ser. Por esta razão, possibilita ao sujeito lançar-se ao que não sabe. Assim, o desenvolvimento profissional docente com idosos se compõe de movimentos de ação, reação e invenção do que se sabe e do que se faz.

\section{A linguagem enquanto acesso ao mundo do educando}


Uma outra dimensão importante a ser levada em conta nas ações da professora é a perspectiva de linguagem por ela assumida.

Tomando de empréstimo uma perspectiva de linguagem apresentada por Bakhtin e Voloshinov (2004), pode-se apreender das atividades pedagógicas propostas pela professora Ana a consciência da importância de assumir a linguagem verbal como constituidora da vocação humana de produzir mundos e, ao mesmo tempo, ser produzida por eles, como tão bem lembra Freire (1982) - a vocação para ser mais, sempre a partir do outro e dos outros, que nos constituem e nos povoam, com palavras e sentidos.

Assim, tanto o outro que narra o que sou como o que narro do outro, constituem-se o legado humano de narrativas e linguagens a produzirem o humano possível que pode vir a existir em nós, como um todo, e cada um, em particular.

Bakhtin (2003), com suas palavras, sempre e modestamente constituídas no diálogo com seus inúmeros outros, nomeados ou não, indica que a construção do trabalho da própria linguagem e do que a linguagem pode apresentar, toma o diálogo como o locus constitutivo dessa forma de inscrição do humano no mundo dos sentidos e das concretudes, que tanto produz a vida, como também produz o que se diz como vida e a ela dá sentido, porque também sobre esse sentido se diz algo.

A professora Ana, ao favorecer que seus estudantes idosos contassem suas histórias, possibilitou que estas histórias narradas fizessem parte do seu horizonte de possibilidades docente e com isso, ao fazerem parte também da história de vida da docente, constituiu novos horizontes de aprendizagem e ensino junto aos seus estudantes.

Esta escuta alteritária, vislumbrada por Bakhtin (2003) e também por Benjamin (1994), produz uma possibilidade de inscrição alteritária que provoca e promove novas relações, novos horizontes de possibilidades, novas faíscas a vislumbrarem o futuro, novas Olh@res, Guarulhos, v. 2, n. 2, p. 424-448. Dezembro, 2014. 
compreensões do vivido, novas articulações entre a professora Ana, seus outros, como os estudantes idosos, ela como outro destes estudantes e outro dela mesma, em seu processo de desenvolvimento profissional.

A linguagem, compreendida enquanto um texto polifônico e dialógico, é um conceito bakhtiniano que permite examinar a questão da alteridade enquanto presença de um outro discurso no interior do discurso. Sua originalidade consiste no fato de colocar o contexto de enunciação no interior do enunciado. (AMORIM, 2004)

A pesquisa narrativa deve garantir isto: que o contexto esteja presente; que as muitas vozes que compõem uma pesquisa estejam asseguradas; enfim, essa polifonia que permite que os sujeitos sejam constituídos por outros e por suas vivências e que constituam-se com os seus outros.

Pode-se fundamentar muito da pesquisa narrativa com Bakhtin (2003), uma vez que essa carrega vários sujeitos. É um texto polifônico a medida em que para escrever, volta-se ao vivido de uma outra maneira, porque já se é outro e, assim, dedica-se um olhar exotópico para aquilo que foi vivido; e, ainda, ao escrevê-las, dá-se acabamentos provisórios a si mesmo e a diferentes situações.

Esse algo, pronunciado ou mudo, exprime o principal critério de acabamento na medida em que ele permite uma resposta. $\mathrm{O}$ acabamento é o que torna possível a resposta do outro ao enunciado. Ou ainda, a reposta do outro indica o acabamento de um enunciado (AMORIM, 2004)

Bakhtin (2003) explica que:

A consciência do autor é a consciência da consciência, isto é, a consciência que abrange a consciência e o mundo da personagem, que abrange e conclui essa consciência da personagem com elementos por princípio transgredientes/exotópicos a ela mesma. (p.11)

Olh@res, Guarulhos, v. 2, n. 2, p. 424-448. Dezembro, 2014. 
Dessa maneira, ao possibilitar que os estudantes idosos narrassem suas experiências, a professora Ana colocou-se neste outro lugar, olhando para o vivido com certo distanciamento, tendo acesso à consciência dos estudantes quando do ocorrido e, mais, dando-a um certo acabamento, ao estar num lugar exotópico determinado, enxergando novas razões e construindo movimentos de abertura e estabilidade na relação pedagógica estabelecida.

Ao adentrar a linguagem dos estudantes idosos e acessar os mundos por eles construídos via linguagem manifestada em suas histórias de vida, a professora não só conseguiu construir sentidos outros possíveis para sua ação docente, como também gerou a possibilidade de uma interação que constituiu-se de aprendizagem e ensino para todos os participantes da relação pedagógica: professora e estudantes.

\section{Considerações Finais}

$\mathrm{Na}$ escrita desse texto, procurou-se analisar o conceito de experiência e de linguagem na educação de idosos. Para tanto, narrouse a trajetória de uma professora com o objetivo de explicitar uma discussão sobre tais conceitos nas práticas pedagógicas e, ao fazê-lo, evidenciou-se: a necessidade de determinadas condições de trabalho; o encontro da experiência docente e discente; a escuta alteritária e a questão da linguagem no desenvolvimento profissional docente.

No que se refere às condições de trabalho, faz-se importante enfatizar que elas interferiam de forma significativa na maneira como a professora pensava, planejava e atuava pedagogicamente. Através dos relatos registrados nos relatórios da professora, verificou-se que quando as condições de trabalho tornaram-se mais adequadas, foi possível para a profissional dar maior atenção a outros aspectos fundamentais, uma vez que os problemas estruturais deixavam de ser uma preocupação Olh@res, Guarulhos, v. 2, n. 2, p. 424-448. Dezembro, 2014. 
constante. Faz-se importante ressaltar que estas condições não são determinantes, mas dificultam ou facilitam, de forma marcante, o pensar e fazer docente.

Quanto ao conceito de experiência abordado, destaca-se que há uma experiência do aluno, bem como existe a do professor, contudo é em um processo relacional que ambas encontram-se, então emerge a experiência que constitui o desenvolvimento profissional docente. $\mathrm{Ou}$ seja, ela surge, também, a partir de uma relação entre professores e alunos.

Destaca-se, ainda, que no caso dos alunos idosos, o processo de compartilhar experiências é fundamental para o envolvimento dos sujeitos com seu próprio processo de aprendizagem, visto que a linguagem por eles manifestada possibilita que o professor ou professora possam adentrar no mundo da vida por eles construído e com isso produzir uma escuta alteritária com o intuito de apreender seus diferentes modos e sentidos linguajeiros.

Sinaliza-se que é essencial considerar a relevância de um olhar estratégico para o desenvolvimento profissional docente no sentido de potencializá-lo em seu aspecto coletivo no interior do espaço educativo, seja ele a unidade escolar ou não. É necessário construir um projeto de trabalho para que questões vivenciadas em sala de aula sejam objeto de discussão e produção de conhecimentos.

Afirma-se, contudo, que ao dizer, nesse texto, que o desenvolvimento profissional do educador acontece fundamentalmente no interior do espaço educativo, não se deixa de reconhecer as potencialidades de outros tempos e espaços. Entretanto, faz-se importante reconhecer o valor deste conceito que se dá sob as dimensões pessoais, profissionais e, inclusive, organizacionais.

Certamente, os conceitos de experiência e linguagem permitem perceber a transformação dos alunos através das suas narrativas e histórias de vida. Ao articular as experiências que, insistentemente, 
emergem na relação de ensino e aprendizagem a uma compreensão de linguagem enquanto acesso ao mundo, foi possível evidenciar necessidades essenciais ao desenvolvimento profissional docente na Educação de Idosos.

O trabalho docente constitui-se como mote do desenvolvimento profissional, ou seja, a própria natureza do fazer pedagógico com idosos é que movimenta tal processo. Contudo, não se trata de algo dado: destaca-se a importância de assumir a necessidade do emergir das experiências dos idosos e docentes. O desenvolvimento profissional é potencializado quando o encontro de experiências acontece. Porém, tal encontro requer tempo, reflexão, disposição, interesse, implicação: elementos contrários em uma sociedade de consumo, pautada nas prerrogativas do capital. Tornar estas condições possíveis e favoráveis é responsabilidade, também, das políticas públicas educacionais: condições de trabalho, de produção de conhecimento, de formação.

Portanto, a compreensão do desenvolvimento dos sujeitos idosos na perspectiva aqui apresentada, gera, necessariamente, um outro compromisso docente e, consequentemente, convoca novos modos de desenvolvimento pessoal e profissional na Educação de Idosos. 


\section{Referências}

AMORIM, M. O pesquisador e seu Outro. Bakhtin nas Ciências Humanas. 1. ed. São Paulo: Musa, 2004.

BAKHTIN, M. Estética da Criação Verbal. São Paulo: Martins Fontes, 2003.

BAKHTIN, M. e VOLOSHINOV, V. Marxismo e Filosofia da Linguagem. 3. ed. São Paulo: Hucitec, 2004.

BENJAMIN, W. Magia e técnica, arte e politica:ensaios sobre literatura e história da cultura. 7. ed. São Paulo: Brasiliense, 1994.

CANÁRIO, R. Educação de Adultos:um campo e uma problemática. Lisboa: Educa, 2000.

A escola: o lugar onde os professores aprendem. Revista do Programa de estudos Pós-graduados em Psicologia da Educação. Pontifícia da Universidade Católica de São Paulo. São Paulo: Educ, n 06, p. 10-27, 1996.

FINGER, M. e ASÚN, J. M. A Educação de Adultos numa Encruzilhada. Aprender a nossa saída. Porto: Porto Editora. Colecção Ciências da Educação, 2003.

FREIRE, P. Pedagogia do Oprimido.11. ed. Rio de Janeiro:Paz e Terra, 1982.

GARCIA, C. M. A formação de professores: novas perspectivas baseadas na investigação sobre o pensamento do professor. In: NÓVOA, A. (Org.) Os professores e sua formação. Lisboa: Publicações D. Quixote, 1995. p. 51-76.

GAZOLI, D. G. D.Afetividade e Condições de Ensino na Educação de Jovens e Adultos. Dissertação de Mestrado. Campinas: Faculdade de Educação da UNICAMP, 2013.

GIOVANNI, L. M. O ambiente escolar e ações de formação continuada.In: CHAVES, S.M., TIBALLI, E.A. (Orgs) Concepções e práticas em formação de professores:diferentes olhares. Rio de janeiro: DP\&A, 2003. p. 207-224.

IMBERNÓN, F. Formação Docente e Profissional:Formar-se para a mudança e aincerteza. São Paulo: Cortez, 2004.

LARROSA, J. Notas sobre a experiência e o saber de experiência. In: GERALDI, C. M. G.; RIOLFI, C. R.; GARCIA, M. de F. (Orgs) Escola Viva: elementos para a construção de uma educação de qualidade social. Campinas: Mercado de Letras, 2004. p. 113-151.

LEITE, S. A. S. Desenvolvimento profissional do professor: desafios institucionais.In: AZZI, R. G., BATISTA, S. S., SADALLA, A.M. F. A. (Orgs.) Formação de Professores:Discutindo oEnsino dePsicologia. Campinas: Editora Alínea, 2000. 180 p Olh@res, Guarulhos, v. 2, n. 2, p. 424-448. Dezembro, 2014. 
LÜDKE, M.; ANDRÉ, M.E.D.A.. Pesquisa em Educação: abordagens qualitativas. São Paulo: EPU, 1986.

NÓVOA, A.; FINGER, M. O método (auto)biográfico e a formação. Lisboa: MS/DRHS/CFAP, 1988.

NÓVOA, A.. Professor: imagens do futuro presente. Lisboa: Educa, 2009.

. Formação de professores e profissão docente. In: NÓVOA, A. (Org.) Os professores e sua formação. Lisboa: Publicações D. Quixote, 1995. p. 15-34.

OLIVEIRA, L. A acção-investigação e o desenvolvimento profissional dos professores: um estudo no âmbito da formação contínua. In: SÁ-CHAVES, I. (Org.) Percursos de Formação e Desenvolvimento Profissional. Portugal: Porto Editora, 1997. p. 91-107.

PEREIRA, E. M.A., LEITE, S. A. S. Formação continuada de professores: os desafios para as redes municipais de ensino. In: Centros de Formação continuada de professores em municípios. Atas. Anais do seminário. Faculdade de Educação da UNICAMP, 2003. p. 01-05.

ROMANELLI, O. O.História da Educação no Brasil.37. ed. Petrópolis: Vozes, 2012.

NÓVOA, A.; FINGER, M.O método (auto)biográfico e a formação. Lisboa: MS/DRHS/CFAP, 1988.

NÓVOA, A.. Professor: imagens do futuro presente. Lisboa: Educa, 2009.

. Formação de professores e profissão docente. In: NÓVOA, A. (Org.) Os professores e sua formação. Lisboa: Publicações D. Quixote, 1995. p. 15-34.

VICENTINI, A. A. F.Narrativas Autobiográficas de professores-formadores na Educação de Jovens e Adultos:lugares reinventados em comunhão. Universidade Estadual de Campinas. Tese de Doutorado. 2012. 